\title{
Pesquisa bibliométrica e hierarquias do conhecimento em Ciência Política
}

Bibliometric research and hierarchies of knowledge in political science

\section{Introdução}

A Ciência Política contemporânea caracteriza-se por uma pluralidade de academias. Desde sua institucionalização formal nos Estados Unidos da América no começo do século XX, os estudos políticos ampliaram seu espaço a ponto de se constituírem como disciplina autônoma em diversos países. Evidentemente, o pioneirismo e o tamanho da academia norte-americana influenciaram, em larga medida, não só como as demais academias se estruturaram, mas também a própria forma que a Ciência Política internacional assumiu. Isto é particularmente visível na maneira como a produção de conhecimento é organizada e divulgada, principalmente por meio dos periódicos especializados.

Nos últimos tempos, mais especificamente desde meados dos anos 1990, a estrutura da disciplina e sua própria história vêm sendo entendidas e analisadas por meio de pesquisas bibliométricas. Estas alicerçam-se no princípio de que o conhecimento publicado nos canais de divulgação científica representa as agendas e o modus operandi da academia, bem como as estruturas de

\footnotetext{
1 Doutor em Ciência Política pela Universidade Federal do Rio Grande do Sul (UFRGS). Professor Adjunto da Universidade da Integração Internacional da Lusofonia Afro-Brasileira (Unilab/Malês), São Francisco do Conde, BA, Brasil. E-mail: <lenine@unilab.edu.br>

2 Doutora em Ciência Política pela Universidade Federal do Rio Grande do Sul (UFRGS). Professora do Ensino Básico, Técnico e Tecnológico do Instituto Federal de Educação, Ciência e Tecnologia Baiano (IFBaiano), Bom Jesus da Lapa, BA, Brasil. E-mail: <melina.morschbacher@ifbaiano.edu.br> Revista Brasileira de Ciência Política, no 31. Braślia, janeiro - abril de 2020, pp 123-160.
} 
incentivo e desincentivos frente ao que se considera ciência e se valida como conhecimento científico. Na Ciência Política, estudos como o de Norris (1997), Breuning e Sanders (2007), Leite (2015), Metz e Jäckle (2017), Mörschbächer (2018), Ravecca (2019), Rocha Carpiuc (2016), Teele e Thelen (2017), Lima et al. (2018) e relatórios de periódicos como os de Ishiyama (2015) e Jacoby et al. (2017), mostram a importância da pesquisa bibliométrica para a compreensão do próprio fazer da ciência política, especificamente no que tange a preferências por teorias e métodos; e, outrossim, ao desenvolvimento e crescimento de áreas de pesquisa.

Entretanto, para além do mapeamento da produção de conhecimento em uma disciplina, a pesquisa bibliométrica cumpre uma outra função de suma relevância para debates e cismas latentes. Ao evidenciarem preferências teóricas e metodológicas, tais pesquisas demonstram que existe uma distribuição desigual de reconhecimento operando na disciplina. O impacto imediato é a geração de incentivos que privilegiam atores envolvidos com aquelas teorias e aqueles métodos que mais são publicados e, portanto, validados como "ciência". Trata-se de um problema que afeta a pluralidade de visões e perspectivas dentro de uma disciplina cada vez mais global e diversa, na qual, a despeito de influências históricas, várias formas de conhecimento se manifestam, inclusive em tons críticos ao que por vezes se considera um modelo central.

Agrava o problema da pluralidade a existência de um problema de diversidade. A pesquisa bibliométrica vem demonstrando que boa parte do conhecimento em Ciência Política é produzido por grupos de pessoas com características semelhantes, o que em si invisibiliza outros atores e, consequentemente, seus discursos e visões. Existe um déficit de representatividade de gênero, raça e origem regional, apenas para mencionar algumas das clivagens mais recorrentes em estudos bibliométricos. A expansão da Ciência Política para todo o globo não foi acompanhada de uma democratização da divulgação de conhecimento, impactando não só na invisiblização de temas e abordagens epistemológicas de grupos historicamente minoritários 
na disciplina; como também nas carreiras e na estrutura de incentivos às mesmas.

Neste contexto, o presente artigo alicerça-se sobre a seguinte pergunta: como os estudos bibliométricos evidenciam as desigualdades na distribuição de reconhecimento e prestígio na Ciência Política? De forma a responder a esta questão, debatemos os principais fundamentos e achados da pesquisa bibliométrica em Ciência Política à luz dos mais recentes cismas metodológicos na disciplina. Estes foram reativados em grande medida com o Movimento Perestroika nos anos 2000 e com a iniciativa de Data Access and Research Transparency (DA-RT). ${ }^{3}$ A DA-RT constitui-se como uma política de acesso a dados e transparência que, embora necessária para lidar com os crescentes problemas de falsas pesquisas, evidencia hierarquias de conhecimento na Ciência Política. Na verdade, a ideia de hierarquias de conhecimento é articulada neste artigo como a estrutura de desigualdades de reconhecimento e prestígio produzida pelos problemas de falta de pluralidade e diversidade de perfis profissionais na disciplina. Essa chave conceitual permite analisar sob uma perspectiva crítica os achados das pesquisas bibliométricas, extrapolando a descrição dos dados ao mesmo tempo que proporciona um espaço para discussão de como e por quem a academia é estruturada.

$\mathrm{O}$ artigo está estruturado da seguinte forma. A seção seguinte introduz o conceito de hierarquias de conhecimento, contextualizando os debates metodológicos na disciplina e as questões de diversidade. $\mathrm{O}$ conceito de hierarquias de conhecimento demonstra-se fundamental em nosso argumento para analisar e interpretar os resultados das pesquisas bibliométricas. Em seguida, tratamos da pesquisa bibliométrica, discutindo como ela é produzida, qual sua importância para compreender as trajetórias históricas da disciplina e quais os achados mais relevantes em termos metodológicos na Ciência Política. Recorremos a dados de nossas pesquisas, bem

3 Além destas iniciativas, destacam-se outras propostas descentralizadoras, como os encontros internacionais da International Political Science Association e movimentos de caráter regional, como o Manifesto de Popayan na América Latina. 
como a estudos bibliométricos recentes e representativos não só desse tipo de investigação, como também de determinados achados de fundamental importância para a compreensão do estado atual da disciplina em diferentes níveis (nacional, regional e internacional). Finalmente, debatemos os achados da diversidade profissional nestas pesquisas e a política da ciência ensejada nas hierarquias de conhecimento, contrapondo-a com as evidências de estudos bibliométricos.

\section{Hierarquias do conhecimento: desigualdades na produção de conhecimento}

Da mesma forma como os estudos bibliométricos permitem visualizar o desenvolvimento histórico de uma disciplina, eles também evidenciam a existência de hierarquias tanto na forma como na agência da produção do conhecimento. No que tange à forma, as hierarquias se manifestam por meio de preferências temáticas, teóricas e metodológicas que acabam favorecendo a publicação daquilo que é considerado científico em detrimento daquilo que não o é. Já a agência refere-se a quem tem espaços na publicação e divulgação do conhecimento, conferindo protagonismo a determinados agentes em detrimento de outros.

A principal e mais conhecida manifestação das hierarquias de conhecimento está associada aos debates quantitativo-qualitativo na Ciência Política. Desde que a Revolução Comportamentalista na academia norte-americana rompeu com o modelo eminentemente descritivo e filosófico dos fenômenos políticos na primeira metade do século XX, a Ciência Política (bem como outras disciplinas que passaram por revolução semelhante) viu-se diante de novas fronteiras metodológicas, alicerçadas primariamente sobre uma concepção newtoniana de ciência (EASTON, 1962; FARR, 1995; KIRKPATRICK, 1962; MERRIAM, 1921; PERES, 2008a, 2008b). $\mathrm{O}$ desenvolvimento dos surveys e testes estatísticos produziu uma onda de pesquisas na academia da nascente Ciência Política nos Estados Unidos da América, influenciando posteriormente as academias europeias, latino-americanas, asiáticas e africanas. $\mathrm{O}$ 
modus operandi da pesquisa comportamentalista era revolucionário na medida em que tratava o esforço científico como um processo próximo ao de uma empiria à la ciências exatas. Naquele momento, entender a política perpassava a análise dos inputs e outputs no sistema político, nomeadamente o comportamento dos agentes que o compunham.

Durante o Comportamentalismo - como ficou conhecido este movimento paradigmático na Ciência Política -, os modelos estatísticos e as grandes bases de dados tornaram-se rotina (PERES, 2008b). As abordagens quantitativas passaram a ser dominantes na disciplina, colocando em segundo plano não só os métodos interpretativos e descritivos de momentos anteriores, como também o esforço por teorização política (HAWKESWORTH, 2015). Este, na verdade, ganha uma nova face com a teoria da escolha racional, considerada a única teoria dedutiva nas ciências sociais e cuja característica mais marcante é a abordagem metodológica por modelos formais (HINDMOOR; TAYLOR, 2015; ERIKSSON, 2011). Tais modelos tornam-se, em determinado momento (especificamente na década 1980), proeminentes nos principais periódicos acadêmicos da disciplina nos EUA. A American Political Science Review (APSR) e a Public Choice, por exemplo, passam a publicar extensivamente análises de escolha racional com modelos matemáticos (LENINE, 2018). Desta forma, esta abordagem metodológica e os modelos estatísticos acabaram por predominar nos principais canais de divulgação de pesquisas na Ciência Política norte-americana, determinando uma rota preferencial para a produção de conhecimento na disciplina. Como salienta Hawkesworth (2015, p. 28):

Dada a hierarquia de poder estabelecida dentro da disciplina na sequência da revolução comportamentalista, "o caminho" para o conhecimento tem sido frequentemente apresentado como se fosse descomplicado, isento de valores e incontestável. ${ }^{4}$

4 Given the established power hierarchy within the discipline in the aftermath of the behavioral revolution, "the way" to knowledge has often been presented as if it were uncomplicated, valueneutral, and uncontestable. (Tradução dos autores) 
Esta onda de pesquisas quantitativas na Ciência Política estabeleceu-se de forma definitiva quando Gary King, Robert Keohane e Sydney Verba (doravante, KKV) publicaram o livro Designing Social Iquiry, em 1994. A obra, considerada um dos mais influentes manuais de metodologia na disciplina até hoje, defende, ainda que menos declaradamente do que creem seus autores, uma lógica de pesquisa e, por conseguinte, de ciência aplicável a todos os estudos dos fenômenos políticos (KING et al., 1994). Fundada numa perspectiva da estatística inferencial e dos métodos quantitativos, a proposta de KKV defende uma ciência social que necessita destes aportes metodológicos para lidar com a complexidade do mundo e, principalmente, para evidenciar relações de causalidade (DOWDING, 2016). Evidentemente, esta forma de se conceber ciência é apenas uma frente à pluralidade de abordagens metodológicas na disciplina e não por acaso provocou reações das mais variadas entre aqueles que não se viram contemplados na proposta da obra (GEORGE; BENNETT, 2005; GOERTZ; MAHONEY, 2012). Ainda sobre este tema, Dowding (2016, p. 162) afirma:

Até certo ponto, (...) o debate moderno foi lançado por King et al. (1994) e sua pretensão de que exista uma lógica de inferência. A implicação subjacente à lógica de inferência é que somente a evidência quantitativa pode (a) apontar a causalidade e (b) testar hipóteses derivadas da teoria. Uma resposta tem sido que a evidência qualitativa pode apontar a causalidade (c) preenchendo as lacunas e ajudando a demonstrar mecanismos reais e $(\mathrm{d})$ apontando um modelo distinto de causalidade. De modo interessante, parcialmente como resultado deste debate, os estudos quantitativos estão sob um escrutínio crescente de suas afirmações de causalidade, 
o que tem levado a novas técnicas estatísticas e ao momento experimental. ${ }^{5}$

Entretanto, os métodos quantitativos e os modelos formais representam - de forma desigual - apenas uma parte da pluralidade da produção acadêmica em Ciência Política. Desde pelo menos o retorno das análises institucionais de cunho histórico-sociológico que já se notava uma insatisfação com os rumos metodológicos da disciplina. Em 1994, com a publicação do livro Pathologies of Rational Choice Theory, de Donald Green e Ian Shapiro, veio à luz o descontentamento com a importância dada à teoria da escolha racional e seus modelos formais. Porém, foi em 2000 que um evento singular colocou em evidência um novo cisma metodológico na disciplina.

Nesse ano, os membros da American Political Science Association (APSA) receberam um e-mail anônimo assinado por Mr. Perestroika. O conteúdo da mensagem, escrita de forma crítica e assertiva, questionava os rumos teóricos e metodológicos da disciplina, bem como os perfis dos pesquisadores da associação e dos presidentes da mesma. Mr. Perestroika atacou o viés quantitativista e formal sublinhado em críticas anteriores e, mesmo sem usar a terminologia de hierarquias de conhecimento, inaugurou um novo momento na academia norte-americana (e, posteriormente, na Europa e na América Latina) para se refletir acerca das preferências da produção de conhecimento. Iniciaram-se debates sobre o tema, retomando a história da Ciência Política, suas concepções de ciência, a construção das agendas de pesquisa, as preferências metodológicas e a (falta de) diversidade racial e de gênero não só nos quadros institucionais, como também nas epistemologias da disciplina (SHAPIRO

5 To some extent, (...) the modern debate was set off by King et al. (1994) and their claim that there is one logic of inference. The underlying implication of the logic of inference is that only quantitative evidence can (a) pin down causation and (b) test hypotheses drawn from theory. One response has been that qualitative evidence can pin down causation by (c) filling in the gaps and helping to demonstrate actual mechanisms and (d) using a different model of causation. Interestingly, partly as a result of the debate, quantitative studies have come under increasing scrutiny of their causal claims, leading to new statistical techniques and the experimental turn. (Tradução dos autores) 
et al., 2004; CATERINO; SCHRAM, 2006; FLYVBJERG, 2006; JACKSON, 2006; SCHRAM, 2006; SCHWARTZ-SHEA, 2006).

Embora difuso, o Movimento Perestroika logrou êxito em expor um problema caro à Ciência Política, qual seja, o de hierarquias na produção de conhecimento e no perfil dos atores envolvidos. Em um primeiro momento, as reclamações dos cientistas políticos norte-americanos se traduziram na edição, por parte da APSA, de uma nova revista que contemplasse os pesquisadores das tradições qualitativa e interpretativa. A Perspective on Politics (POP), desde sua fundação, alinhou-se aos princípios do Movimento e conferiu a si mesma a missão de representar os descontentes com o tipo de ciência publicado na APSR (HOCHSCHILD, 2003). Não é por acaso que a revista se devotou a conferir um espaço para outras modalidades de ciência distintas das preferências "hegemônicas". Como declara Jeffrey Isaac (2005, p. 931), ex-editor da POP:

Recebemos muitas submissões que procedem nessa maneira de 'ciência normal', algumas delas muito boas, e as revisamos periodicamente internamente e geralmente as devolvemos a seus autores com incentivo para enviar suas obras a um dos muitos periódicos em nossa disciplina - APSR, AJPS, JoP, CPS - que tende a publicar 'descobertas' no formato padrão da ciência normal. ${ }^{6}$

Apesar de não articular conceitualmente a linguagem de hierarquias de conhecimento, o Movimento Perestroika serviu de alerta para questões fundamentais no desenvolvimento da disciplina. Porém, mesmo os debates que o movimento produziu não foram suficientes para impedir a iniciativa idealizada e protagonizada pela APSA de formulação de uma política editorial mais ampla, com impactos no sistema de incentivos e desincentivos às escolhas

\footnotetext{
We receive many submissions that proceed in this 'normal science' manner, some of them very good, and we expeditiously review them internally and typically return them to their authors with encouragement to submit their pieces to one of the many journals in our discipline-APSR, AJPS, JoP, CPS-that does tend to publish'findings' in the standard, normal science format. (Tradução dos autores)
} 
teóricas e metodológicas dos pesquisadores. Proposta inicialmente como uma emenda ao Guia Ético da associação, cujo objetivo consistia em fundamentar políticas mínimas de acesso a dados e transparência, a iniciativa tomou forma por meio de quatro documentos que estabelecem diretrizes sobre a produção de conhecimento na Ciência Política, recebendo o nome conjunto de DA-RT (APSA 2012; LUPIA; ELMAN, 2014; GOLDER; GOLDER, 2016; SCHWARTZ-SHEA; YANOW, 2016). A Declaração de Transparência dos Editores de Periódicos (Journal Editors Transparency Statement, no original, JETS) ${ }^{7}$ estabelece um conjunto de compromissos de garantia de acesso a dados e de transparência secundado pelos editores de 29 revistas de alto fator de impacto nos EUA e na Europa. Como documento aberto para a assinatura, e dado o seu caráter internacional, o JETS, assim como as demais diretrizes estabelecidas nos outros documentos que constituem a iniciativa DA-RT, promove um determinado perfil de ciência, favorecendo não só determinadas abordagens metodológicas em detrimento de outras, como também afetando as comunidades de cientistas políticos de maneira abrangente (HALL, 2016; HTUN, 2016; FUJII, 2016; YASHAR, 2016). Persiste a preocupação de que os vagos termos da DA-RT, alicerçados sobre políticas mais facilmente implementadas por aqueles que subscrevem aos métodos quantitativos, produzam incentivos para que um tipo de ciência prevaleça sobre outro. O impacto é potencialmente profundo, visto que epistemologias vinculadas a grupos minoritários frequentemente recorrem a abordagens metodológicas qualitativas e interpretativas. Tais questões não são pacificadas no conteúdo da DA-RT, o que resultou em um amplo debate na academia norte-americana, apresentando ecos em espaços como a International Political Science Association (IPSA) e as academias da América Latina (LENINE; MÖRSCHBÄCHER, 2019).

Frente a esses eventos recentes, autores de diferentes nacionalidades e filiações acadêmicas vêm investigando as formas como a

7 O texto da declaração pode ser acessado em: <https://www.dartstatement.org/2014-journal-editorsstatement-jets>. Acesso em: 13 de novembro de 2018. 
produção de conhecimento na Ciência Política tem assumido um caráter desigual. É como resultado destas pesquisas que emerge o conceito de hierarquias de conhecimento, o qual se insere no debate mais amplo da existência de uma política da ciência (FUJII, 2016; MÖRSCHBÄCHER, 2018; RAVECCA, 2010, 2014, 2019). O uso específico do termo também tem sido evidenciado especialmente quando há o questionamento direto da existência de uma estrutura de privilégios acadêmicos muito mais ampla do que o debate quanti-quali tradicional. Recentemente, por ocasião do $24^{\circ}$ Congresso Mundial da IPSA, "hierarquias de conhecimento" serviu de nome para um painel de pesquisa referente às críticas aos perfis metodológicos e teóricos na disciplina. O mesmo intitulava-se "The Politics of Political Science: Pluralism or Hierarchies of Knowledge?” [A Política da Ciência Política: Pluralismo ou Hierarquias do Conhecimento?]. Não por acaso, e como resultado deste painel, a IPSA publicou em sua própria revista - a International Political Science Review (IPSR) - um relatório que apresenta uma análise bibliométrica dos dados dos artigos nela publicados e postos em perspectiva com o cenário de publicação global da disciplina (LIMA et al., 2018). Todos estes debates e movimentos demonstram não só a existência de hierarquias de conhecimento na disciplina, como a necessidade de compreendê-los como parte de um fenômeno comum.

\section{Pesquisa bibliométrica: fundamentos e achados metodológicos}

Como mencionado anteriormente, os estudos bibliométricos perfazem as pesquisas que buscam categorizar, segundo critérios variados, a produção bibliográfica dentro de uma área de conhecimento ou disciplina. Os objetivos e enfoques destes estudos são variados, mas no geral suas categorias visam a abarcar questões teórico-metodológicas e clivagens profissionais. Por tal razão, as categorias estabelecidas nestes estudos devem ser transversais aos temas, às teorias e aos métodos utilizados pelos membros da comunidade científica analisada; bem como aos profissionais que a constituem. 
No caso específico da Ciência Política, as categorias utilizadas resultam da comparação entre diversos trabalhos já publicados sobre o tema e no próprio processo de categorização de revistas nacionais e internacionais. Evidentemente, como toda e qualquer proposta de classificação, existem limites na capacidade de abarcar a pluralidade de abordagens temáticas, teóricas e metodológicas de uma disciplina, principalmente considerando-se o nível de globalização do conhecimento e de diálogo crítico entre academias. De todo modo, os diferentes estudos bibliométricos vêm convergindo para classificações comuns, como se notam nos relatórios de Ishiyama (2015) e Jacoby et al. (2017); e nos estudos de Campos et al.. (2017), Norris (1997), Lima et al. (2018), Lenine (2018), Mörschbächer (2018) e Nicolau e Oliveira (2017). Isto abre espaço para futuras iterações, o que é de fundamental importância para a compreensão da história da disciplina. Se a Ciência Política constrói-se por meio daquilo que é publicado, estudos bibliométricos que atravessam a existência da disciplina permitem visualizar as mudanças temáticas, teóricas e metodológicas que ocorrem na mesma. Com isso, entende-se a disciplina como uma construção dinâmica, com a ascensão e queda de determinadas preferências teóricas e metodológicas.

Cada academia de Ciência Política narra sua história em diferentes momentos da mesma. É comum que as associações devotem projetos e espaços para tal, algo que se nota, por exemplo, na iniciativa de John Gunnell (2004) para compreender a história da disciplina no contexto da democracia americana e da APSA; no Manifesto de Popayan na Ciência Política da América Latina (BULCOURF et al., 2015); na iniciativa da Associação Brasileira de Ciência Política em resgatar a trajetória histórica da disciplina no país (MILANI et al., 2016), apenas para citar alguns. Nesses espaços, a história da disciplina é construída, em larga medida, por aqueles que a vivenciaram, vez que suas experiências e trânsitos fornecem informações valiosas sobre o desenvolvimento da mesma, bem como facilitam a construção de uma narrativa contínua.

Entretanto, faz-se mister reconhecer que se uma narrativa pode demonstrar continuidade, não se deve ignorar a existência 
de tensões no seu desenvolvimento. A Ciência Política é construída por meio de debates temáticos, teóricos e metodológicos, os quais se refletem no próprio processo de narrar tal história. $\mathrm{O}$ caso da história da Ciência Política norte-americana ilustra esse fenômeno: a narrativa histórica mais tradicional fundamenta-se na existência de paradigmas que se sucedem e coexistem, redirecionando agendas de pesquisa e colocando em proeminência determinadas abordagens teóricas e metodológicas em detrimento de outras (ALMOND, 1998; GOODING; KLINGEMANN, 1998; GUNNELL, 2006; MÖRSCHBÄCHER, 2018; PERES, 2008a, 2008b; SOMMIT; TANNEHAUS, 1976).

Nesse contexto, as pesquisas bibliométricas cumprem um papel especial ao evidenciarem as manifestações concretas de tais movimentos temáticos, teóricos e metodológicos dentro da disciplina. Nas pesquisas de Lima et al. (2018), Mörschbächer (2018) e Lenine (2018), bem como nas demais da literatura internacional especializada, as categorias metodológicas têm-se demonstrado mais proeminentes para a avaliação das relações entre as narrativas históricas da disciplina e o output de publicações, o principal meio de divulgação de conhecimento acadêmico. O enfoque em métodos, mais do que em temas e teorias, permite a realização de comparações entre diferentes periódicos e academias, além de atacar um dos principais motores das hierarquias de conhecimento na Ciência Política, qual seja, as hierarquias no campo da produção acadêmica. Nesse sentido, faz-se mister apresentar alguns achados fundamentais para a compreensão do problema em tela. Eles retratam o cenário internacional a partir das tendências de revistas de prestígio na disciplina, servindo, inclusive, como referência em debates locais, regionais e internacionais. São importantes na medida em que permitem a visualização, sob um ponto de vista comparativo, de tendências na produção do conhecimento em diferentes espaços.

No cenário dos periódicos de alto fator de impacto, evidencia-se uma tendência de preferências por estudos baseados em métodos quantitativos (ISHIYAMA, 2015; JACOBY et al, 2017; LENINE; MÖRSCHBÄCHER, 2019; LIMA et al., 2018; NORRIS, 1997). Em 
termos absolutos, é possível avaliar comparativamente os dados para os anos mais recentes e verificar a transversalidade de tal fenômeno. A Figura 1 apresenta os valores percentuais de artigos com metodologia quantitativa e qualitativa publicados nos últimos anos em quatro periódicos internacionais.

Figura 1. Distribuição de artigos quanti e quali em periódicos internacionais

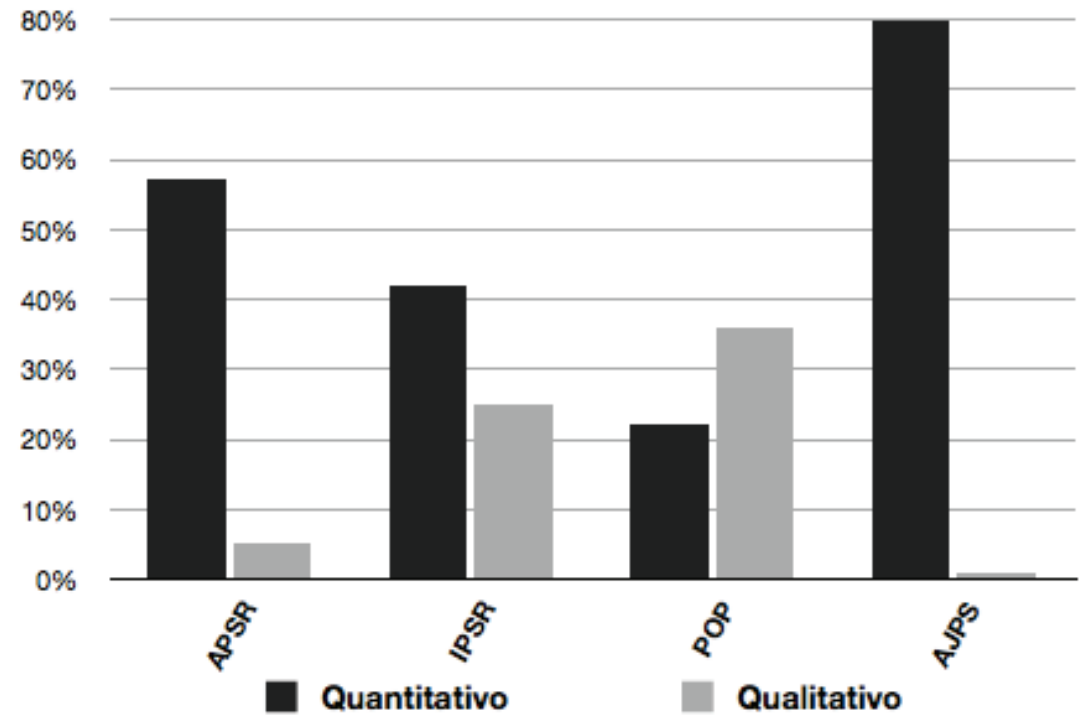

Fonte: Elaboração dos autores com dados contidos em Ishiyama, 2015; Jacoby et al, 2017; Lima et al., 2018. Os dados para a APSR, a AJPS e a IPSR referem-se ao período 2010-2016; para a POP, 2008-2012. Observação: AJPS: American Journal of Political Science; APSR: American Political Science Review; IPSR: International Political Science Review; POP: Perspectives on Politics.

Como se nota na Figura 1, há uma predileção por métodos e abordagens da tradição quantitativa, excetuando-se, ainda que com limites, a POP. O quantitativismo como modelo de desenho de pesquisa vem crescentemente assumindo proeminência na disciplina pelo menos desde os anos 1990, como mostra a Figura 2 com os dados da APSR, AJPS e IPSR, os três como periódicos de circulação na disciplina pré-Movimento Perestroika (como mencionado anteriormente, a POP surge como resposta ao Movimento 
Perestroika, acomodando abordagens eminentemente qualitativas). Essas tendências, embora restritas aos casos em tela no âmbito deste artigo, vêm sendo apontadas em outras revistas e contextos nacionais.

Figura 2. Evolução da divisão quanti-quali, 1990-2015

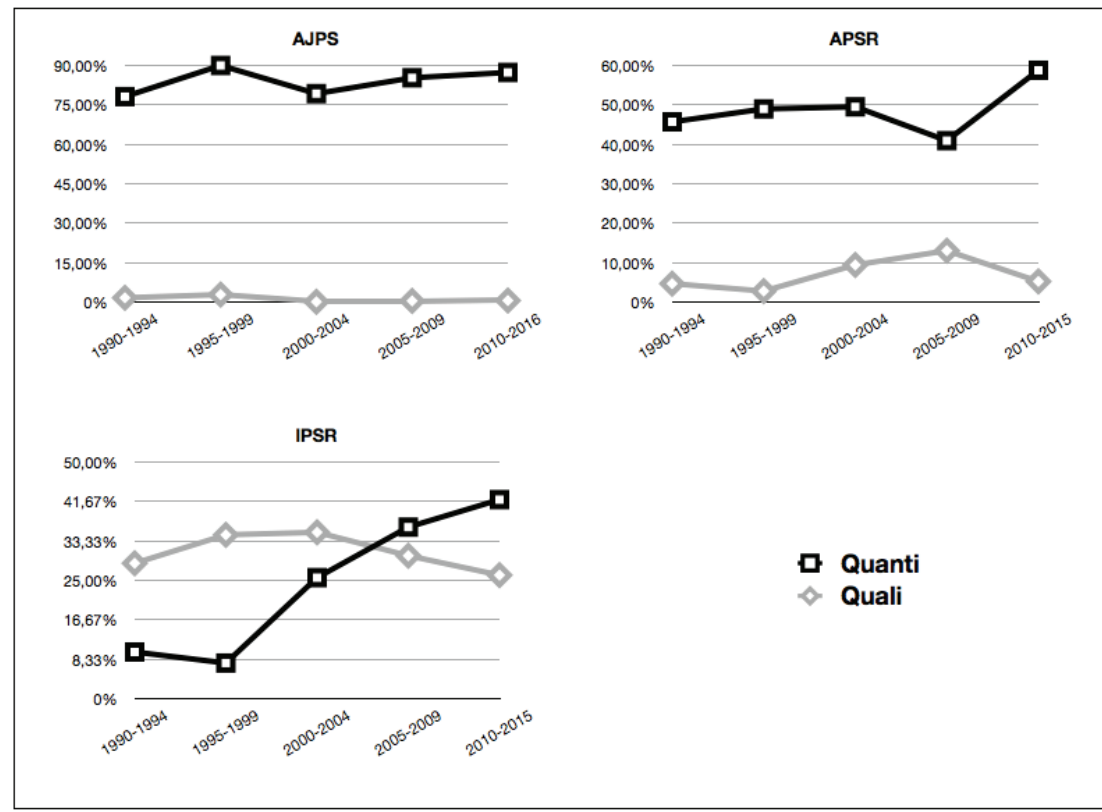

Fonte: Elaboração dos autores. Observação: AJPS: American Journal of Political Science; APSR: American Political Science Review; IPSR: International Political Science Review.

A predileção pelas abordagens quantitativas faz com que os debates atuais centrem-se especificamente nos seus efeitos nos sistemas de incentivos e constrangimentos na academia. Schwartz-Shea e Yanow (2016), escrevendo sobre a DA-RT, chamam a atenção para o fato de que tais predileções produzem incentivos aos novos pesquisadores para que orientem suas pesquisas para as metodologias que desfrutam de maior receptividade nos periódicos 
de prestígio, o que, por consequência, afeta o espaço de trabalhos das abordagens qualitativa e interpretativa.

No Brasil, o cenário é bastante variado e a disciplina de Ciência Política ainda carece de estudos bibliométricos alinhados com os debates internacionais para que se possa realizar um diagnóstico acerca dos cenários de publicação no país. Muito do que se tem produzido nacionalmente - bem como na região da América Latina - concentra-se principalmente na caracterização de temas e dos perfis profissionais (MADEIRA; MARENCO, 2016; MAGLIA, 2016; MARENCO, 2014; MÖRSCHBÄCHER, 2018; ROCHA CARPIUC; MADEIRA, 2019). Os estudos recentes de Fernando Leite (2016) e de Jairo Nicolau e Lilian Oliveira (2017) suprem precisamente este espaço de diálogo com as análises bibliométricas internacionais, oferecendo um panorama temático e metodológico dos principais periódicos brasileiros de Ciência Política. Como se nota na Figura 3 , estes autores convergem para resultados semelhantes no que tange às preferências temáticas da academia brasileira, ainda que suas classificações quanto às áreas temáticas sejam distintas. ${ }^{8} \mathrm{Na}$ verdade, essa é uma dificuldade perene em qualquer análise bibliométrica, visto que a definição do que são temas ou áreas temáticas é alvo de constante disputa pela comunidade científica. Como Leite sugere:

Áreas são conjuntos mais ou menos institucionalizados de objetos de pesquisa relacionados. Elas são o principal fator na organização da produção: definem a margem de objetos sujeitos a estudo, condicionando o possível conjunto de fenômenos a serem estudados. A estrutura das áreas, portanto, representa uma gama de objetos mais ou menos legítimos os mais legítimos sendo, em geral, os mais importantes e/ou os mais tradicionais. É basicamente a resposta da disciplina às perguntas 'o que estudar' e 'o que deve ser estudado'

8 Leite (2016) subdivide suas categorias ilustradas nos gráficos em 26 subcategorias. Nicolau e Oliveira (2017) subdividem suas categorias em 25 subcategorias. 
- definindo, em larga medida, a identidade da disciplina. ${ }^{9}$ (Leite, 2016, p. 5)

Figura 3. Preferências temáticas da Ciência Política brasileira

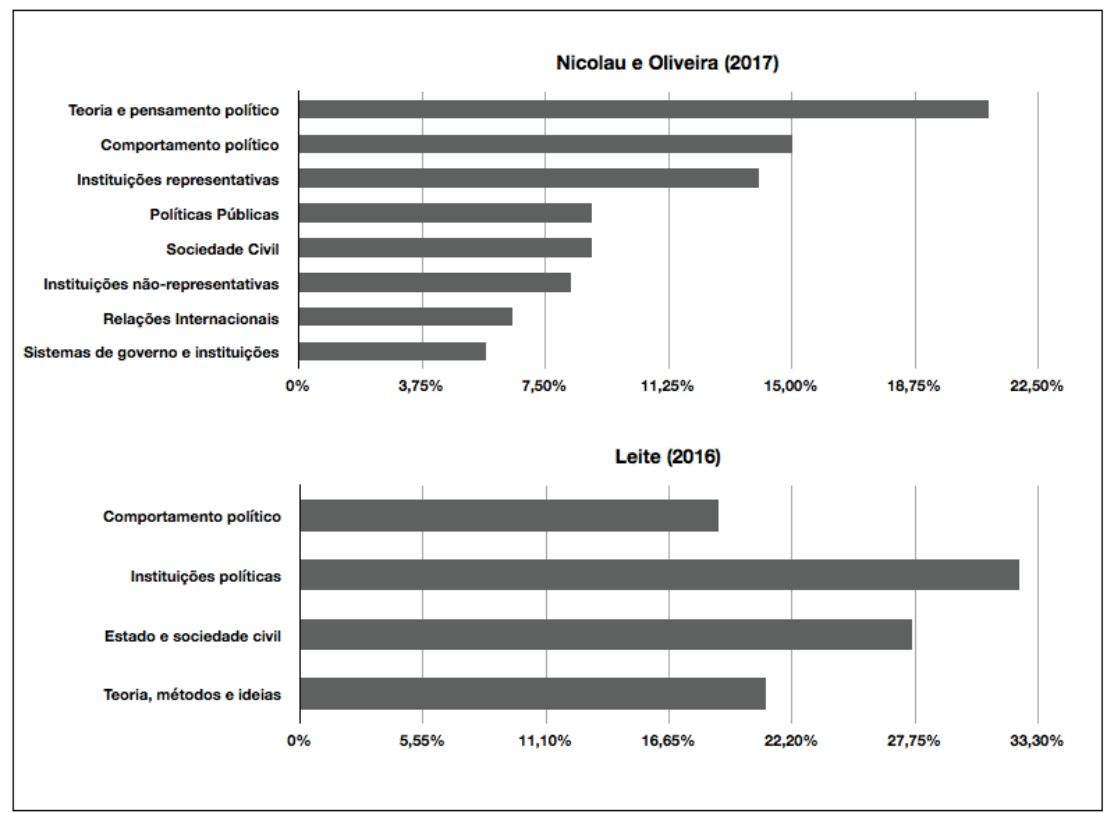

Fonte: Leite (2016) e Nicolau e Oliveira (2017).

No que tange à questão metodológica, Nicolau e Oliveira (2017) apresentam dados específicos quanto às abordagens quantitativas na Ciência Política brasileira e a diversidade de técnicas estatísticas, buscando identificá-las e avaliar seu grau de utilização nos periódicos analisados. Em larga medida, seus achados demonstram que

9 "Areas are more or less institutionalized sets of related research objects. They are the leading factor in the organization of production: they define the margin of objects subject to study, conditioning the possible set of phenomena to be studied. The structure of areas thus represents a range of more or less legitimate objects - the most legitimate, in general, being the most valuable and/or the most traditional. It is basically the discipline's answer to the questions 'what to study'and 'what should be studied' - largely defining the identity of the discipline." (Tradução dos autores) 
há uma prevalência na série histórica de estatística básica (44\% dos artigos quanti), seguida do uso de estatística avançada (18\% referem-se ao uso de índices e correlação), análise de regressão (12\%) e análise multivariada (4\%) (NICOLAU; OLIVEIRA, 2017, p. 384). Porém, ao analisarem artigos qualitativos por meio de três categorias de métodos quali (observação participante e entrevistas; grupos focais; história oral), esses autores verificaram que uma porcentagem muito limitada se enquadra nesta abordagem. Resultado semelhante é observado na pesquisa de Medeiros et al. (2016), que se debruçaram sobre o campo de Relações Internacionais, o qual compartilha tanto a área de avaliação na Coordenação de Aperfeiçoamento de Pessoal do Ensino Superior (CAPES), como também periódicos de prestígio para publicação na região da América Latina. Estes autores verificaram a prevalência da não especificação de métodos nos artigos sul-americanos analisados, respondendo por $87,1 \%$ de todo o seu corpus de material. Em contrapartida, métodos quantitativos ocorreram em 4,8\% dos artigos e métodos qualitativos, em $6,2 \%$.

De certa forma, o argumento de Gláucio Soares (2005) de que a Ciência Política brasileira carece de adequado treinamento metodológico e que os cientistas políticos brasileiros produzem textos quantitativos e não-quantitativos (id est, sem nenhuma abordagem metodológica vinculada às tradições qualitativa e interpretativa) parece se sustentar frente aos achados de Medeiros et al. (2016) e Nicolau e Oliveira (2017). Ademais, esta predileção metodológica por métodos quantitativos associa-se às tendências observadas internacionalmente, como no caso dos periódicos supracitados.

A análise bibliométrica, de todo modo, vem demonstrando a ampla preferência por determinados tipos de metodologia e desenho de pesquisa. Os dados de periódicos de alto prestígio (medido pelo fator de impacto e pelo Sistema Qualis, no caso brasileiro) apontam para um momento que favorece o uso de métodos quantitativos. Tal preferência enseja as hierarquias de conhecimento na disciplina de Ciência Política, com profundos impactos na forma como a própria ciência da política é concebida; como também nas carreiras dos 
cientistas políticos, especificamente na sua vinculação a temáticas, teorias e métodos.

\section{As hierarquias de conhecimento nas pesquisas bibliométricas}

As pesquisas bibliométricas apontadas até aqui concentraram-se primariamente no resultado concreto da produção acadêmica, focando-se nomeadamente nas preferências metodológicas e temáticas dos trabalhos publicados nas revistas. Elas evidenciaram, senão uma tendência generalizada (dada a quantidade limitada de revistas analisadas), ao menos uma tendência consistente em periódicos de alto fator de impacto na disciplina. Os dados nas séries temporais (Figura 2) demonstram que os métodos quantitativos ampliaram seu espaço nas páginas das revistas, o que produziu movimentos de questionamento dos perfis editoriais das mesmas; do conceito de ciência avançado na disciplina; da marginalização de abordagens metodológicas alternativas, mais precisamente a qualitativa e a interpretativa. São pontos associados ao que se entende por uma ciência da política, com profundos impactos na maneira como a pesquisa é conduzida, desde sua concepção na forma de uma inquietação; como também na sua condução, por escolhas metodológicas que privilegiam uma tradição específica. Como resume Hakwesworth (2015, p. 29):

Precisamente porque a observação é compreendida como replicação exata, as estratégias para a aquisição do conhecimento são ditas "neutras" e "desprovidas de valor". Nesta visão, as investigações científicas podem capturar a realidade objetiva, vez que a subjetividade dos observadores individuais pode ser controlada pela sua rígida adesão 
a procedimentos neutros no contexto de experimentos sistemáticos, deduções lógicas e análise estatística de dados. ${ }^{10}$

No que tange às preferências teóricas, é notório que as pesquisas bibliométricas ainda não tenham explorado com profundidade este aspecto. Uma das dificuldades refere-se ao uso polissêmico do termo "teoria", o qual se refere não só às correntes teóricas consagradas e reconhecidas na disciplina, mas também a hipóteses e conjecturas explicativas. Em periódicos de alto fator de impacto, tais como a APSR e a AJPS, o espaço para artigos teóricos tem-se mantido de forma consistente, geralmente apresentando trabalhos que versam sobre filosofia política clássica, liberalismo, teoria política positiva, teoria da justiça etc. De todo modo, quando comparado ao espaço devotado a trabalhos empíricos, verifica-se que a teoria encontra-se secundarizada. Evidentemente, há periódicos devotados primordialmente às produções teóricas, tais como Political Theory e Journal of Theoretical Politics, porém, a questão que se levanta no contexto das hierarquias de conhecimento - no qual os periódicos desfrutam de diferentes níveis de prestígio e reconhecimento - reside justamente no fato de que a teoria ocupa um lugar de menor relevância dentro da onda de trabalhos empíricos, sobremaneira quantitativos. No caso brasileiro, a situação da teoria se encontra em nível semelhante. Segundo a plataforma Qualis, apenas duas revistas brasileiras carregam explicitamente o termo "teoria" em seus títulos nas classificações mais altas (A1, A2, B1 e B2): Teoria \& Sociedade (B1) e Teoria \& Pesquisa (B2). ${ }^{11}$ Embora isso não signifique que artigos teóricos não sejam publicados em outros periódicos brasileiros (como apontado na Figura 3), o fato de apenas duas revistas se dedicarem explicitamente à teoria indica uma dispersão dos

10 Precisely because observation is understood as exact replication, strategies for the acquisition of knowledge are said to be "neutral" and "value-free". In this view, scientific investigations can grasp objective reality, because the subjectivity of individual observers can be controlled through rigid adherence to neutral procedures in the context of systematic experiments, logical deductions, and statistical analysis of data. (Tradução dos autores)

11 Acessado em 6 de novembro de 2018 para o quadriênio 2013-2016. 
artigos do gênero, representando um desafio para o mapeamento das preferências teóricas na disciplina no país.

A questão das predileções temáticas é ainda mais complexa dentro da disciplina. De certa forma, os relatórios de periódicos como AJPS, APSR e POP oferecem um panorama de quais temas são proeminentes em suas páginas. Entretanto, a diversidade da Ciência Política no nível internacional se traduz em uma variedade de temas, o que se vê em periódicos de cunho mais internacional, como a IPSR (LIMA et al., 2018) e a European Journal of Political Research (NORRIS, 1997). É notório que os periódicos nacionais prefiram os temas de política nacional, o que faz com que AJPS e APSR, que encabeçam a lista de classificação por fator de impacto, publiquem mais artigos sobre política americana (ISHIYAMA, 2015; JACOBY et al., 2017). De todo modo, as pesquisas bibliométricas não têm explorado com profundidade as preferências temáticas, abrindo espaço para novas categorizações e estudos. $\mathrm{O}$ desafio, porém, consiste na formulação de categorias que sejam representativas da disciplina e que possam ser analisadas comparativamente entre vários periódicos.

Como se pode notar, os avanços no campo da produção acadêmica estão acompanhados de desafios a serem superados em estudos bibliométricos futuros. No entanto, é no que tange ao perfil profissional que se vêm encontrando evidências de determinados perfis de pesquisadores e de estruturas de privilégio de produção acadêmica, bem como desafios de ordem metodológica da própria pesquisa bibliométrica. $\mathrm{O}$ caráter eminentemente masculino e branco da academia norte-americana sinaliza a necessidade de se realizarem não só estudos sobre estas estruturas, como também uma profunda autocrítica sobre como e por quem o conhecimento é produzido (FUJII, 2016). Situação semelhante se verifica na procedência dos autores e das autoras em periódicos de alto prestígio: majoritariamente são norte-americanos e europeus ocidentais (LIMA et al., 2018). Nesse sentido, a análise do perfil profissional é tão fundamental para a compreensão das dinâmicas de poder e prestígio dentro da Ciência Política, como da produção acadêmica. 
Um dos grandes desafios para a análise de perfis profissionais refere-se à atribuição de gênero, raça e etnia aos pesquisadores. Como se tratam de elementos da identidade que demandam auto-reconhecimento por parte dos indivíduos, a atribuição por um terceiro pode assumir um caráter arbitrário. No entanto, algumas estratégias vêm sendo utilizadas com sucesso, especialmente para a clivagem de gênero. Teele e Thelen (2017), por exemplo, recorreram a um algoritmo computacional para, com base nos nomes das autoras e coautoras, identificar o gênero. Nas pesquisas de Lima et al. (2018) e Mörschbächer (2018), recorreu-se aos currículos de cada pesquisador, buscando-os nos sites oficiais das instituições onde trabalham. Embora erros possam ocorrer, ambas abordagens são efetivas para solucionar, ainda que não completamente, $o$ problema da auto-identificação.

Independentemente da abordagem utilizada para lidar com a identificação de gênero, os resultados encontrados não só no âmbito das pesquisas de Mörschbächer (2018) e Lima et al. (2018), como em outras, apontam para uma persistente desigualdade na publicação de artigos autorados e coautorados por mulheres, seja em colaboração com homens, seja em colaboração unicamente com mulheres (BREUNING; SANDERS, 2007; ROCHA CARPIUC, 2016; TEELE; THELEN, 2017). As mulheres ainda representam uma parcela pequena das autorias e coautorias de artigos, como se nota na Figura 4, que apresenta os dados compilados de pesquisas que abordaram esta questão tanto em periódicos internacionais de língua inglesa, quanto em periódicos latinoamericanos e brasileiros. Em todos estes casos, um aparente teto de vidro limita a presença feminina nas páginas de revistas influentes na disciplina. 
Figura 4. Distribuição de artigos por gênero

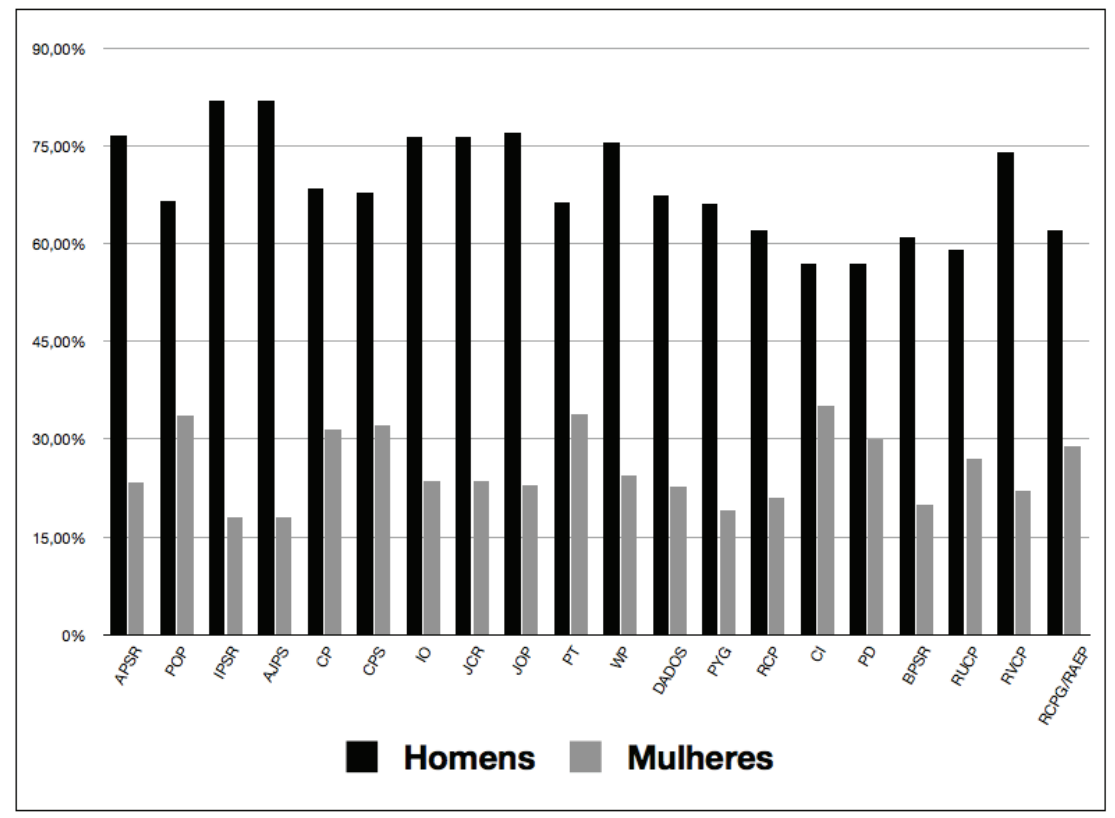

Fonte: Campos et al. (2017, p. 635), Lima et al. (2018), Rocha Carpiuc (2016, p. 12), Teele e Thelen (2017, p. 435). Observação: APSR: American Political Science Review; POP: Perspectives on Politics; IPSR: International Political Science Review; AJPS: American Journal of Political Science; (P: Comparative Politics; (PS: Comparative Political Studies; I0: International Organizations; JCR: Journal of Conflict Research; JOP: Journal of Politics; PT: Political Theory; WP: World Politics; DADOS: DADOS - Revista de Ciências Sociais; PYG: Política y Gobierno; RCP: Revista de Ciencia Política; Cl: Colombia Internacional; PD: Revista PostData; BPSR: Brazilian Political Science Review; RUCP: Revista Uruguaya de Ciencia Política; RVCP: Revista Venezolana de Ciencia Política; RCPG/ RAEP: Revista de Ciencia Política y Gobierno/Revista Andina de Estudios Políticos.

Os problemas da identificação de gênero e da baixa representatividade são mais complexos quando se trata das clivagens de raça e etnia. Dificilmente os currículos contêm esse tipo de informação e a avaliação por imagens (fotos dos autores) acarretaria um enorme grau de arbitrariedade - além de ignorar as diversas formas como as pessoas negociam suas identidades e o reconhecimento das mesmas. De todo modo, a questão étnico-racial tem despertado o interesse de vários estudiosos no contexto da Ciência Política norte-americana, com trabalhos tratando da baixa representatividade de diversos grupos, tais como afroamericanos, latinos, 
asiáticos e nativos-americanos (ALEXANDER-FLOYD et al., 2015; ALEX-ASSENSOH et al., 2005; ARDS; WOODARD, 1992, 1997; ÁVALOS, 1991; MARTINEZ-EBERS et al., 2000; MCCORMICK, 2012; RICH, 2007; SINCLAIR-CHAPMAN, 2015). O contexto histórico racial nos EUA, porém, produziu uma concentração nos estudos sobre pesquisadores negros e negras, bem como nesse eixo para a compreensão dos temas de raça e etnia nos artigos. Na Figura 5, nota-se a disparidade da presença de negros na presidência da APSA ao longo de sua existência; e na Figura 6, a evolução das publicações sobre raça e etnia na APSR e POP.

Figura 5. Presença de negros na presidência da APSA

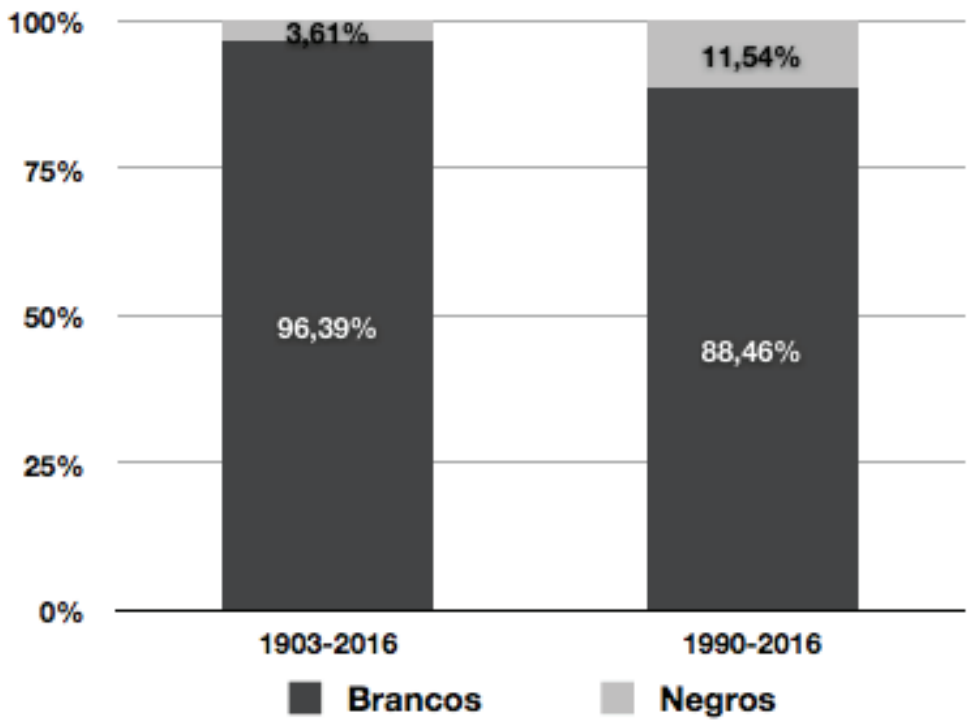

Fonte: Elaborado com base em Mörschbächer (2018). 
Figura 6. Evolução de artigos publicados na APSR e na POP sobre raça e etnia [\%]

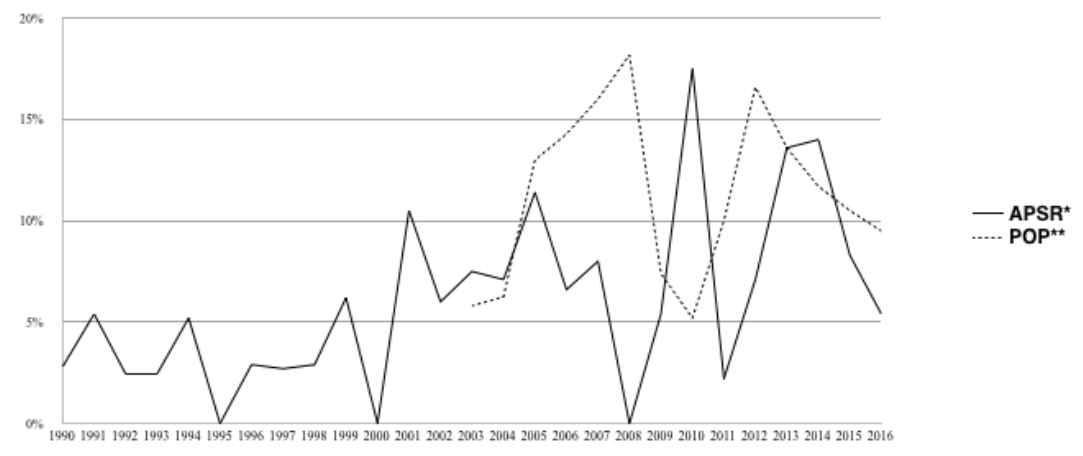

Fonte: Elaborado com base em Mörschbächer (2018). *Dados de 1990-2016; **Dados de 2003-2016.

É interessante salientar a importância da representatividade de membros das clivagens supracitadas para a construção do conhecimento. Embora se reconheça que identificação não é prerrogativa para o estudo de um determinado tema, ela parece ser relevante para que os próprios temas que interessam às mulheres, aos negros, aos LGBTs e a outros grupos não-representados tenham espaço nas publicações e nas conferências. No que tange às questões de gênero, observa-se na APSR, POP e IPSR que, se não fossem pelas mulheres, estes debates não seriam trazidos, como ilustra a Figura 7. Nela, nota-se que a vasta maioria dos artigos publicados sobre gênero são autorados e coautorados por mulheres, com pouquíssimas contribuições de autores homens. Destarte, por mais que a prerrogativa da vivência não implique em primazia temática e científica, ela desempenha um papel crucial para que as questões a ela associadas se concretizem em pesquisas e publicações. $\mathrm{O}$ problema da baixa representatividade na disciplina - seja ela de raça, gênero ou etnia - pode ser compreendido no contexto da política de presença: conferir-lhes espaço é fundamental para que as temáticas que tangem às vivências e experiências destas pessoas sejam levadas ao debate acadêmico (PHILLIPS, 1998). 
Figura 7. Distribuição por sexo de artigos sobre gênero em três periódicos

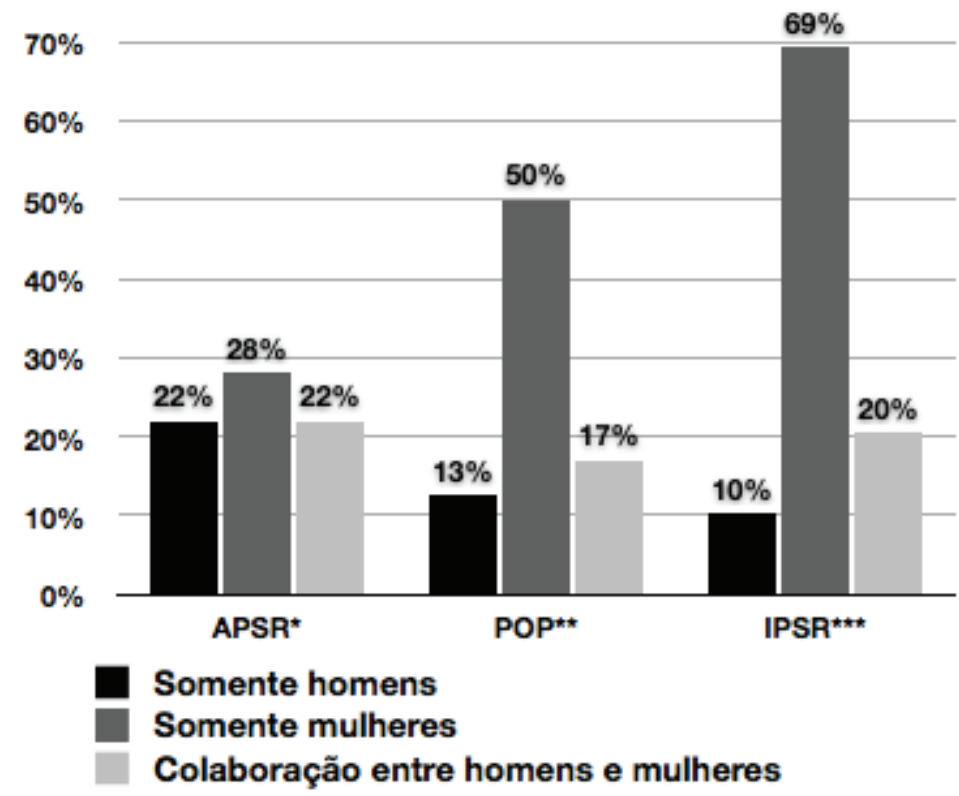

Fonte: Elaboração própria com base em dados de Lima et al. (2018) e Mörschbächer (2018). *Dados de 1990-2016; **Dados de 2003-2016; ***Dados de 1980-2015.

Para além das questões de gênero e raça e seus impactos na visibilidade de grupos e temáticas, há também um problema no que tange à representação regional nas revistas. No caso norte-americano, é notório que maioria das publicações sejam autoradas por pesquisadores das maiores instituiçõos de ensino, coincidentemente as que mais recebem recursos e incentivos para a condução de pesquisa (MÖRSCHBÄCHER, 2018; SCHWARTZ-SHEA; YANOW, 2016). No cenário mais internacional, subsiste uma desigualdade nas publicações da Europa e EUA, de um lado, e do resto do mundo, de outro. Os dados da IPSR são emblemáticos neste sentido: entre 2010 e 2015, 74,7\% dos artigos publicados na revista vieram das academias da América do Norte e da Europa Ocidental, como mostra a Figura 8. Esta desigualdade de representação, que apresenta uma tendência consistente no tempo, tem profundos 
impactos na medida em que dificulta a divulgação de epistemologias locais, assim como temáticas que interessam às populações das regiões fora dos eixos acadêmicos tradicionais.

Figura 8. Distribuição regional de artigos da IPSR, 2010-2015

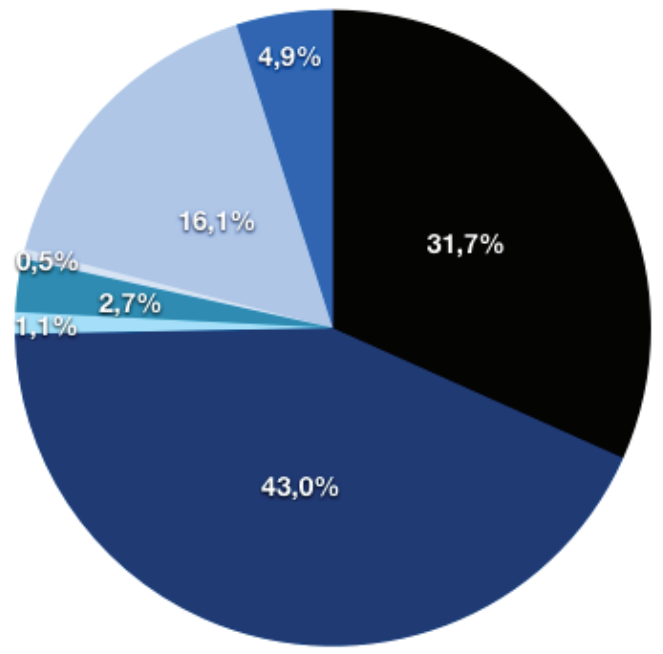

América do Norte

Europa Ocidental

Europa Central e Oriental

América Latina

África

Ásia

Oceania

Fonte: Elaboração dos autores com base em Lima et al. (2018).

Esses resultados não representam uma simples coincidência de dados, como se essa organização institucional das academias da disciplina fosse fortuita. A persistência das dificuldades de representatividade de gênero, raça e origem regional demonstra que o fenômeno possui raízes sólidas dentro das academias de Ciência Política, produzindo as disparidades apontadas acima. Compreender estas dificuldades como parte de um problema mais amplo de hierarquias do conhecimento permite analisar as consequências mais profundas do fenômeno, nomeadamente: 1 . os obstáculos persistentes que se interpõem às mulheres, que já constituem uma parcela significativa da academia de Ciência Política na América do Norte, na Europa e na América Latina (ROCHA CARPIUC, 2016; ROCHA CARPIUC; MADEIRA, 2019; TEELE; THELEN, 2017$) ; 2$. 
a baixa inclusão de negros nas academias norte-americana e brasileira, como resultado do racismo estrutural e sistemático presente em ambas as sociedades (FUJII, 2016; GOMES, 2009); 3. a preponderância das epistemologias e metodologias norte-americanas e europeias frente a outras formas de produção do conhecimento, constituindo um obstáculo à descolonização do conhecimento nos principais meios de divulgação do mesmo (SANTOS; MENESES, 2009); 4. a sinalização de preferências teóricas e metodológicas com maior acesso aos periódicos, produzindo incentivos e desincentivos às novas gerações de cientistas políticos (SCHWARTZ-SHEA; YANOW, 2016).

Tais pesquisas, em síntese, revelam as hierarquias de conhecimento operantes na disciplina. As evidências que se acumulam com estes estudos e apresentadas anteriormente indicam as persistentes desigualdades na Ciência Política, o que reafirma a importância de pesquisas bibliométricas que assumam uma perspectiva crítica para além do diagnóstico do estado da arte da produção de conhecimento. Ora, se as publicações são a moeda para a progressão e o sucesso da carreira, fechar as portas para perspectivas plurais e grupos específicos - identificados por gênero, raça, etnia e origem regional - significa produzir e legitimar um sistema de incentivos e desincentivos na academia, além de perpetuar as posições daqueles que se beneficiam das abordagens e clivagens preponderantes nos periódicos.

\section{Considerações finais}

As pesquisas bibliométricas revelam as hierarquias do conhecimento na disciplina de Ciência Política e a maneira como as mesmas se manifestam. Determinadas impressões sobre os perfis profissionais e preferências metodológicas que reverberam na academia tendem a ser confirmadas por meio destes estudos que, como demonstramos, vêm apontando as diversas desigualdades no que tange à produção do conhecimento e ao perfil de quem se engaja como pesquisador ou pesquisadora. A persistência de 
flagrantes desigualdades indica que as hierarquias do conhecimento constituem uma parte fundamental da Ciência da Política.

Ao longo do artigo, apresentamos um conjunto de dados oriundos de diversas pesquisas, buscando responder à pergunta sobre como os estudos bibliométricos evidenciam as desigualdades na distribuição de reconhecimento e prestígio na Ciência Política. Os resultados parecem confirmar a imobilidade das estruturas institucionais no que tange ao como é pesquisado e por quem é pesquisado. Esses achados empíricos reforçam a relevância de análises bibliométricas sob uma perspectiva crítica da produção do conhecimento. Para além dos tradicionais debates ensejados por quantitativistas $v s$. qualitativistas, mais especificamente no que foi chamado de "ditadura do método", verifica-se, por meio deste tipo de análise, a necessidade de se incluir com maior ênfase a discussão crítica sobre as desigualdades de gênero, raça, etnia e origens regionais dos pesquisadores. Por se tratar de um debate que extrapola a academia norte-americana, manifestando-se em outras academias nacionais e mesmo em periódicos internacionais, faz-se mister que mais estudos sejam conduzidos de forma a permitir comparações e evidenciar um problema que, a princípio, afeta a Ciência Política em todos os países. Não é por acaso que a IPSA, em seu Congresso Mundial de 2020, dedicou um espaço em sua programação para uma mesa-redonda sobre o tema, intitulada "Diversity and Inclusion in the Discipline: Roundtable on Research Agendas and Approaches" [Diversidade e Inclusão na Disciplina: Mesa-Redonda sobre Agendas de Pesquisa e Abordagens].

Compreendemos, outrossim, que o fenômeno das hierarquias oferece a chave conceitual para a análise e a interpretação dos resultados dos estudos bibliométricos. Nesse sentido, abrem-se agendas de pesquisa em duas frentes fundamentais: internacionalmente, iterações de estudos já realizados e a expansão para mais periódicos, objetivando mapear com maior detalhamento a evolução das desigualdades da produção de conhecimento; e, nacionalmente, com pesquisas que tracem as intersecções entre gênero e método e, principalmente, que identifiquem as origens dos autores e das autoras. 
O uso dos referenciais e evidências aqui propostos permitem estabelecer paralelos entre as pesquisas já realizadas e essas agendas, resultando na construção de um panorama mais amplo da Ciência Política e suas estruturas acadêmicas e profissionais. Como visto com os dados apresentados, o aprofundamento de uma agenda de pesquisa bibliométrica a partir de marcos conceituais e de categorização mínimos é fundamental para que os estudos possam dialogar entre si, uma dificuldade que se mostra persistente e que impõe obstáculos ao esforço comparativo.

\section{Referências}

ALEX-ASSENSOH, Yvette M.; GIVENS, Terri; GOLDEN, Kathie; HUTCHINGS, Vincent L.; WALLACE, Sherri L.; WHITBY, Kenny J. Mentoring and African-American political scientists. PS: Political Science and Politics, v. 38, n. 2, p 283-285, 2005. ALEXANDER-FLOYD, Nikol G.; D’ANDRA OREY, Byron; BROWN-DEAN, Khalilah. Professional conferences and the challenges of studying black politics. PS: Political Science and Politics, v. 48, n. 2, p. 319-323, 2015.

ARDS, Sheila; WOODARD, Maurice. The road to tenure and beyond for African American political scientists. The Journal of Negro Education, v. 66, n. 2, p. 159-171, 1997.

ALMOND, Gabriel A. Political science: the history of the discipline, In: GOODIN, Robert E.; KLINGEMANN, Hans-Dieter (orgs.). A new handbook of political science. Oxford: Oxford University Press, 1998. p. 50-96.

AMERICAN POLITICAL SCIENCE ASSOCIATION - APSA. A guide to professional ethics in political science [online]. 2012. Disponível em: http://www.apsanet.org/portals/54/Files/ Publications/APSAEthicsGuide2012.pdf. Acesso em: 12 de nov. 2018.

ÁVALOS, Manuel. The status of latinos in the profession: problems in recruitment and retention. PS: Political Science and Politics, v. 24 , n. 2, p. 241-46, 1991. 
BREUNING, Marijke; SANDERS, Kathryn. Gender and journal authorship in eight prestigious political science journals. PS: Political Science and Politics, v. 40, n. 2, p. 347-351, 2007. BULCOURF, Pablo; MÁRQUEZ, Enrique Gutiérrez; CARDOZO, Nelson. Historia y desarollo de la ciencia política en américa latina: reflexiones sobre la constitución del campo de estudios. Revista de Ciencia Política, v. 35, n. 1, p. 179-199, 2015.

CAMPOS, Luiz Augusto; FERES JÚNIOR, João; GUARNIERI, Fernando. 50 anos da Revista DADOS: uma análise bibliométrica do seu perfil disciplinar e temático. Dados - Revista de Ciências Sociais, v. 60, n. 3, p. 623-661, 2017.

CATERINO, Brian; SCHRAM, Sanford. Introduction: reframing the debate. In: SCHRAM, Sanford; CATERINO, Brian (orgs.). Making political science matter: debating knowledge, research, and method. Nova Iorque: New York University Press, 2006. p. 1-16.

DOWDING, Keith. The philosophy and methods of political science. Londres, Palgrave, 2016.

EASTON, David. Introduction: the current meaning of "behavioralism" in political science. In: CHARLESWORTH, James C. (org.). The limits of behavioralism in political science. Philadelphia: The American Academy of Political Science, 1962. p. 1-25.

ERIKSSON, Lina. Rational choice theory: potential and limits. Londres: Palgrave Macmillan. 2011.

FARR, James. Remembering the revolution: behavioralism in American Political Science. In: FARR, James; DRYZEK, John S.; LEONARD, Stephen T. (orgs.). Political science in history: research programs and political traditions. Cambridge: Cambridge University Press, 1995. p. 198-224.

FLYVBJERG, Bent. A Perestroikan straw man answers back: David Laitin and phronetic political science. In: SCHRAM, Sanford; CATERINO, Brian (orgs.). Making political science matter: debating knowledge, research, and method. Nova Iorque: New York University Press, 2006. p. 56-85. 
FUJII, Lee Ann. The dark side of DA-RT. Comparative Politics Newsletter, v. 26, n. 1, p. 25-27, 2016.

GEORGE, Alexander L.; BENNETT, Andrew. Case studies and theory development in the social sciences. Cambridge: MIT Press, 2005.

GOERZ, Gary; MAHONEY, James. A tale of two cultures: qualitative and quantitative research in the Social Sciences. New Jersey: Princeton University Press, 2012.

GOLDER, Matt; GOLDER, Sona N. Letter from the editors.

Comparative Politics Newsletter, v. 26, n. 1, p. 2-24, 2016.

GOMES, Nilma Lino. Intelectuais negros e produção do conhecimento: algumas reflexões sobre a realidade brasileira. In: SANTOS, Boaventura de Sousa; MENSES, Maria Paula (orgs.). Epistemologias do Sul. Coimbra: Almedina, 2009. p. 419-441. GOODING, Robert; KLINGEMANN, Hans-Dieter. Political science: the discipline. In: GOODING, Robert; KLINGEMANN, Hans-Dieter. (orgs.). A new handbook of political science. Oxford: Oxford University Press, 1998. p. 3-49.

GREEN, Donald; SHAPIRO, Ian. Pathologies of rational choice theory. New Haven: Yale University Press, 1994

GUNNELL, John. Imagining the American polity: political science and the discourse of democracy. University Park PA: Pennsylvania State University Press, 2004.

GUNNEL, John. The founding of the American Political Science Association: discipline, profession, political theory, and politics. American Political Science Review, v.100, n. 4, p. 479-486, 2006.

HALL, Peter A. Transparency, research integrity and multiple methods. Comparative Politics Newsletter, v. 26, n. 1, p. 28-31, 2016.

HAWKESWORTH, Mary. Contending conceptions of science and politics. In: YANOW, Dvora; SCHWARTZ-SHEA, Peregrine (orgs.). Interpretation and method: empirical research methods and the interpretive turn. Londres: Routledge, 2015. p. 27-49. 
HINDMOOR, Andrew; TAYLOR, Brad. Rational choice. Londres: Palgrave Macmillan, 2015.

HOCHSCHILD, Jennifer L. Editor's note: introduction and observations. Perspectives on Politics, v. 1, n. 1, p. 1-4, 2003. HTUN, Mala. DA-RT and the social conditions of knowledge production in political science. Comparative Politics Newsletter, v. 26, n. 1, p. 32-36, 2016.

ISAAC, Jeffrey C. For a more public political science. Perspectives on politics, v. 13, n. 2, p. 269-283, 2015.

ISHIYAMA, John. Report of the editors of the American Political Science Review, 2013-14. PS: Political Science and Politics, v. 48, n. 2, p. 400-403, 2015.

JACKSON, Patrick T. A Statistician strikes out: in defense of genuine methodological diversity. In: SCHRAM, Sanford; CATERINO, Brian (orgs.). Making Political Science Matter: Debating Knowledge, Research, and Method. Nova Iorque: New York University Press, 2006. p. 86-97.

JACOBY, William G.; LUPTON, Robert N.; ARMALY, Miles T.; ENDERS, Adam. Report to the Editorial Board and the Midwest Political Science Association Executive Council [online], 2017. Disponível em: https://ajpsblogging.files. wordpress.com/2013/05/ajps-2017-annual-report-4-3-17.pdf. Acesso em: 12 nov. 2018.

KING, Gary; KEOHANE, Robert O.; VERBA, Sidney. Designing social inquiry. Princeton: Princeton University Press, 1994. KIRKPATRICK, Evron. The impact of the behavioral approach on traditional political science. In: RANNEY, Austin (org.). Essays on the behavioral study of politics. Urbana: University of Illinois Press, 1962. p. 1-30.

LEITE, Fernando. O campo de produção da ciência política brasileira contemporânea: uma análise histórico-estrutural de seus princípios de divisão a partir de periódicos, áreas e abordagens. Tese (Doutorado em Sociologia). Curitiba: Universidade Federal do Paraná, 2015. 
LENINE, Enzo. Críticas à teoria da escolha racional e hierarquias do conhecimento na ciência política. BIB, v. 85, p.77-103, 2018. LENINE, Enzo; MÖRSCHBÄCHER, Melina. La iniciativa DA-RT en la ciencia política estadounidense: discursos acerca de una política de transparencia y acceso a datos. Revista Mexicana de Ciencias Políticas y Sociales, v. 64, n. 235, p. 109-138, 2019.

LIMA, Enzo; MÖRSCHBÄCHER, Melina; PERES, Paulo. Three decades of the International Political Science Review (IPSR): A map of the methodological preferences in IPSR articles. International Political Science Review, v. 39, n. 5, p. 679-689, 2018.

LUPIA, Arthur; ELMAN, Colin. Openness in political science: data access and research transparency: introduction. PS: Political Science and Politics, v. 47, n. 1, p.19-42, 2014.

MADEIRA, Rafael Machado; MARENCO, André. Os desafios da internacionalização: mapeando dinâmicas e rotas de circulação internacional. Revista Brasileira de Ciência Política, n. 19, p.47-74, 2016.

MAGLIA, Cristiana. A construção acadêmica da ciência política no Brasil: Formação, evolução e perfil da disciplina no Rio Grande do Sul. Dissertação (Mestrado em Ciência Política) Universidade Federal do Rio Grande do Sul, Porto Alegre, 2016. MARENCO, André. The three Achilles' heels of Brazilian political science. Brazilian Political Science Review, v. 8, n. 3, p. 3-38, 2014.

MARTINEZ-EBERS, Valerie; AVALOS, Manuel; HARDY-FANTA, Carol; LOPEZ, Linda; SEGURA, Gary M.; SCHMIDT, Ronald. An update on the status of Latinos y Latinas in political science: what the profession should be doing. PS: Political science and politics, v. 33, n. 4, p. 899-903, 2000.

MCCORMICK, Joseph. Beyond Tactical withdrawal: an early history of the national conference of black political scientists. National Political Science Review, n. 13, p.158-179, 2012. 
MEDEIROS, Marcelo de Almeida; BARNABÉ, Israel; ALBUQUERQUE, Rodrigo; LIMA, Rafael. What does the field of international relations look like in South America? Revista Brasileira de Política Internacional, v. 59, n. 1, p.1-31, 2016. MERRIAM, Charles. The present state of the study of politics. American Political Science Review, v. 15, n. 1, p. 173-185, 1921. METZ, Thomas; JÄCKLE, Sebastian. Patterns of publishing in political science journals: an overview of our profession using bibliographic data and a co-authorship network. PS: Political science and politics, v. 50, n. 1, p. 157-165, 2017.

MILANI, Carlos; AVRITZER, Leonardo; BRAGA, Maria do

Socorro (orgs.). A ciência política no Brasil: 1960-2015. São Paulo: Editora FGV, 2016.

MÖRSCHBÄCHER, Melina. A ciência e a política da ciência: pluralismo intelectual e diversidade profissional na ciência política norte-americana. 246f. Tese (Doutorado em Ciência Política) Instituto de Filosofia e Ciências Humanas, Universidade Federal do Rio Grande do Sul, Porto Alegre, 2018.

NICOLAU, Jairo; OLIVEIRA, Lilian. Political science in Brazil: An analysis of academic articles (1966-2015). Sociologia e Antropologia, v. 7, n. 2, p. 371-393, 2017.

NORRIS, Pippa. Toward a more cosmopolitan political science?

European Journal of Political Research, v. 31, n. 1, p. 17-34, 1997.

PERES, Paulo Sérgio. As abordagens neoinstitucionais da política: uma proposta alternativa de análise classificatória. Revista Versões, v. 3, n. 4, p. 145-178, 2008 a.

PERES, Paulo Sérgio. Comportamento ou instituições: a evolução histórica do neo-institucionalismo da ciência política. Revista Brasileira de Ciências Sociais, v. 23, n. 68. p. 54-71, 2008 b.

PHILLIPS, Anne. The politics of presence. Oxford: Oxford University Press, 1998.

RAVECCA, Paulo. La política de la ciencia política: ensayo de introspección disciplinar desde América Latina hoy. Revista América Latina, n. 9, p. 173-210, 2010. 
RAVECCA, Paulo. La política de la ciencia política en Chile y Uruguay: ciencia, poder, contexto. primeros hallazgos de una agenda de investigación. Documento de Trabajo (Instituto de Ciencia Política da Universidad de la República), n. 1, p.1-30, 2014.

RAVECCA, Paulo. The politics of political science: rewriting Latin American experiences. Nova Iorque: Routledge, 2019.

RICH, Wilbur C. African American political scientists in academic wonderland. In: RICH, Wilbur C. (org.). African American Perspectives on Political Science. Philadelphia: Temple University Press, 2007. p. 38-52.

ROCHA CARPIUC, Cecilia. Women and diversity in Latin American political science. European Political Science, v. 15, n. 4, p. 457-475, 2016.

ROCHA CARPIUC, Cecilia; MADEIRA, Rafael Machado. Desigualdade de gênero, internacionalização e trajetórias acadêmicas na Ciência Política. Civitas, v. 19, n. 3, p 545-563, 2019.

SANTOS, Boaventura de Sousa; MENESES, Maria Paula. Introdução. In: SANTOS, Boaventura de Sousa; MENSES, Maria Paula (orgs.), Epistemologias do Sul, Coimbra: Almedina, 2009. p. 9-19.

SCHRAM, Sanford. Return to politics: perestroika, phronesis, and post-paradigmatic political science. In: SCHRAM, Sanford; CATERINO, Brian (orgs.). Making political science matter: debating knowledge, research, and method. Nova Iorque: New York University Press, 2006. p. 17-32.

SCHWARTZ-SHEA, Peregrine. Conundrums in the practice of pluralism. In: SCHRAM, Sanford; CATERINO, Brian (orgs.). Making political science matter: debating knowledge, research, and method. Nova Iorque: New York University Press, 2006. p. 209-221. 
SCHWARTZ-SHEA, Peregrine; YANOW, Dvora. Legitimizing political science or splitting the discipline? reflections on DA-RT and the Policy-making role of a professional association. Politics and Gender, v. 12, n. 11, p. 1-19, 2016.

SHAPIRO, Ian; SMITH, Rogers; MASOUD, Tarek. Introduction: problems and methods in the study of politics. In: SHAPIRO, Ian; SMITH, Rogers; MASOUD, Tarek. (orgs.). Problems and methods in the study of politics. Cambridge: Cambridge University Press, 2004. p. 1-18.

SINCLAIR-CHAPMAN, Valeria. Leveraging Diversity in Political Science for Institutional and Disciplinary Change. PS: Political science and politics, v. 48, n. 3, p. 454-458, 2015.

SOARES, Gláucio Ary Dillon. O calcanhar metodológico da ciência política no Brasil. Sociologia, Problemas e Práticas, n. 48, p. 27-52, 2005.

SOMIT, Alber; TANNENHAUS, Joseph. The development of American political science: from Burgess to behavioralism. Boston: Allynand Bacon, 1976.

TEELE, Dawn Lagan; THELEN, Kathleen. Gender in the journals: publications patterns in political science. PS: Political Science and Politics, v. 50, n. 2, p. 433-447, 2017.

YASHAR, Deborah J. Editorial trust, gatekeeping, and unintended consequences. Comparative Politics Newsletter, v. 26, n. 1, p. 57-64, 2016.

\section{Resumo}

Como os estudos bibliométricos evidenciam as desigualdades na distribuição de reconhecimento e prestígio na Ciência Política? A relevância de tais estudos reside no fato de que eles revelam as hierarquias de conhecimento relacionadas tanto à forma da produção do conhecimento, no que tange a preferências temáticas, teóricas e metodológicas; quanto à agência dessa produção, especificamente aos perfis profissionais. Nesse sentido, o presente artigo objetiva avançar o conceito de hierarquias de conhecimento como uma estrutura de desigualdades de reconhecimento, prestígio e poder na disciplina, ancorando-se nos resultados de estudos bibliométricos próprios e de outros autores. Apoiamo-nos em dados 
estatísticos bibliométricos para argumentar que tais pesquisas devem ser interpretadas à luz das hierarquias de conhecimento que ensejam, evidenciando as desigualdades existentes na academia, tanto no que tange à produção de conhecimento, como à diversidade dos atores.

Palavras-chave: pesquisa bibliométrica; hierarquias do conhecimento; perfil profissional; produção acadêmica.

\section{Abstract}

How do bibliometric studies unravel the inequalities in terms of recognition and prestige in Political Science? The relevance of such studies resides in the unravelling of the hierarchies of knowledge operating in knowledge-making, especially in terms of thematic, theoretical, and methodological preferences; and in terms of the agency of knowledgemaking, namely professional profiles. Thus, this paper aims to advance the concept of hierarchies of knowledge as the structure of inequalities of recognition, prestige, and power within the discipline. Its explanatory power is grounded in findings from our bibliometric research and that of other authors. We support our argument with statistical data, arguing that bibliometric studies should be interpreted in light of their underlying hierarchies of knowledge, both in terms of knowledge-making, and agency diversity.

Keywords: bibliometric research; hierarchies of knowledge; professional profile; knowledge-making.

Recebido em 29 de novembro de 2018

Aprovado em 08 de março de 2020 
